\title{
https://helda.helsinki.fi
}

Early childhood infections and the use of antibiotics and antipyretic-analgesics in Finland, Estonia and Russian Karelia.

\section{the DIABIMMUNE Study Group}

2019-11

the DIABIMMUNE Study Group, Mustonen , N , Siljander , H, Peet , A, Tillmann , V , Härkönen , T , llonen , J , Hyöty , H \& Knip , M 2019 , ' Early childhood infections and the use of antibiotics and antipyretic-analgesics in Finland, Estonia and Russian Karelia. ' , Acta Paediatrica , vol. 108 , no. 11 , pp. 2075-2082 . https://doi.org/10.1111/apa.14874

http://hdl.handle.net/10138/312939

https://doi.org/10.1111/apa.14874

acceptedVersion

Downloaded from Helda, University of Helsinki institutional repository.

This is an electronic reprint of the original article.

This reprint may differ from the original in pagination and typographic detail.

Please cite the original version. 
PROF. MIKAEL KNIP (Orcid ID : 0000-0003-0474-0033)

Article type : Regular Article

\section{Early childhood infections and the use of antibiotics and antipyretic-analgesics in Finland, Estonia, and Russian Karelia}

Neea Mustonen ${ }^{1,2}$, Heli Siljander ${ }^{1,2}$, Aleksandr Peet ${ }^{3}$, Vallo Tillmann ${ }^{3}$, Taina Härkönen ${ }^{1,2}$, Jorma Ilonen $^{4,5}$, Heikki Hyöty ${ }^{6,7}$, Mikael Knip, ${ }^{1,2,8,9}$, the DIABIMMUNE Study Group*

${ }^{1}$ Children's Hospital, Pediatric Research Center, University of Helsinki and Helsinki University Hospital, Helsinki, Finland

${ }^{2}$ Research Programs Unit, Diabetes and Obesity, University of Helsinki, Helsinki, Finland

${ }^{3}$ Department of Pediatrics, University of Tartu and Tartu University Hospital, Tartu, Estonia

${ }^{4}$ Immunogenetics Laboratory, Institute of Biomedicine, University of Turku, Turku, Finland

${ }^{5}$ Clinical Microbiology, Turku University Hospital, Turku, Finland

${ }^{6}$ Department of Virology, School of Medicine, University of Tampere, Tampere, Finland

${ }^{7}$ Fimlab Laboratories, Pirkanmaa Hospital District, Tampere, Finland

${ }^{8}$ Folkhälsan Research Center, Helsinki, Finland

${ }^{9}$ Tampere Center for Child Health Research, Tampere University Hospital, Tampere, Finland

*The DIABIMMUNE Study Group is listed at the end of the article

Short title: Early infections, medications, and the hygiene hypothesis

\section{Corresponding author}

Mikael Knip, MD, PhD

Professor of Pediatrics

Children's Hospital

University of Helsinki

P.O. Box 22, Fl-00014 Helsinki, Finland

Phone: +3589 47172701

E-mail: mikael.knip@helsinki.fi

This article has been accepted for publication and undergone full peer review but has not been through the copyediting, typesetting, pagination and proofreading process, which may lead to differences between this version and the Version of Record. Please cite this article as doi: 10.1111/apa.14874

This article is protected by copyright. All rights reserved. 


\title{
ABSTRACT
}

Aim: Infections in early childhood are common reasons to seek medical attention. This study compares the prevalence of infections, and the use of antibiotics and antipyretic-analgesics, in children from Finland, Estonia, and Russian Karelia.

Methods: Children with a genetically increased risk for type 1 diabetes $(N=797)$ were observed from birth up to 3 years of age. Illnesses and medications were reported by parents continuously. All reported infections, antibiotics, and antipyretic-analgesics were compared between Finland and Estonia, and to a lesser extent with Russian Karelia, due to poor study compliance.

Results: Compared to Estonians, Finns reported more infections during the first and second years of life. During the follow-up Finnish children had 10 infections while Estonians only had $8(p<0.001)$. Finns also used more antibiotics and antipyretic-analgesics in each year during the follow-up. Russian Karelians reported the lowest frequency of infections and the most infrequent use of antibiotics and antipyretic-analgesics in the first 2 years of life.

Conclusion: Infections and the use of antibiotics and antipyretic-analgesics in early childhood were most frequent in Finland, where socio-economic conditions are the most developed and microbial encounters are sparse. This may reflect on the hygiene hypothesis; a less effective immune system that allows normally harmless microbes to attack and cause clinical infections.

\author{
Abbreviations \\ $\mathrm{CD}$, celiac disease \\ HLA, human leukocyte antigen \\ ICD, International Classification of Diseases \\ T1D, type 1 diabetes
}

Key words: antibiotics, antipyretic-analgesics, childhood infections, the hygiene hypothesis

This article is protected by copyright. All rights reserved. 


\section{Key notes:}

- The aim was to compare the frequency of infections, and the use of antibiotics and antipyretic-analgesics, in children from three countries with significant differences in socioeconomic conditions.

- Compared to Estonians, Finns reported more infections during the first and second years of life, while Russian Karelians reported the lowest number of infections.

- Antibiotics and antipyretic-analgesics were used most frequently in Finland, even in relation to infection frequencies.

\section{INTRODUCTION}

The majority of children suffer from common childhood infections several times during their first years of life. Viral respiratory infections, especially those caused by rhinoviruses, are the most common of such infections $(1,2)$. In spite of the increased awareness regarding the risks caused by antibiotic resistance, antibiotics are frequently prescribed based on obscure clinical pictures, without knowledge of the causative pathogens $(3,4)$. The lax use of broad-spectrum antibiotics is driving a host of microbes towards multiresistance, which is already causing severe clinical problems worldwide (5). Recurrent use of systemic antibiotics disturbs the balance of the intestinal microbiota, causing dysbiosis early in life $(6,7)$, the long-term consequences of which are still unknown. So far, use of antibiotics in early life has been reported to be associated with an increased risk for future asthma $(8,9)$, juvenile idiopathic arthritis (10), neurocognitive disorders (11), and obesity (12).

The hygiene hypothesis (13) suggests that the loss of beneficial microbial encounters in early life may inhibit the normal maturation of the developing immune system, leading to aberrant immune reactions towards harmless antigens, loss of self-tolerance, and outbreak of immune mediated diseases. This hypothesis was tested in the DIABIMMUNE study, in a cohort of Finnish, 
Estonian, and Russian Karelian children with human leukocyte antigen (HLA)-conferred susceptibility to type 1 diabetes (T1D). Our current data presents differences between these three countries regarding childhood infections and their medications. Finland, Estonia, and Russian Karelia share similar seasonal variation, exposure to sunlight, and outdoor temperatures, but differ from each other in their socio-economic circumstances and standard of hygiene (14). Notably, differences between these three countries in the incidence of several immune-mediated diseases, such as T1D, celiac disease (CD), and atopic diseases, are conspicuous (15-19). The study area in Espoo, Finland, presents a fully industrialized and westernized socio-economic environment with high gross domestic product (GDP) per capita and remarkably high standard of living, while Russian Karelia struggles with poor socio-economic conditions. Estonia positions economically between the two other countries, but has since gaining its independence in 1991 continued its rapid socio-economic growth and undergone intense changes in the general standard of living.

\section{METHODS}

Study population. All newborn infants with parental consent born between September 2008 and February 2011 in one hospital in Finland, two hospitals in Estonia, and two hospitals in Russian Karelia were screened for HLA-conferred susceptibility T1D (Figure 1). Children carrying these riskgenotypes were invited to the birth cohort of the DIABIMMUNE study and followed prospectively from birth up to the age of 3 years. From the original 835 children who enrolled in the study, 38 children were excluded due to incomplete data [HLA misclassification $(n=7)$ and no questionnaires answered $(n=31)$ ], leaving 797 children $\left(n_{\mathrm{FIN}}=386 n_{\mathrm{EST}}=322\right.$, and $n_{\mathrm{RUS}}=89$ ) to be included in the current study. The study details have been described elsewhere (20). Briefly, families reported continuously the participating child's infections, use of medications, and other life events in a study diary. The participants attended clinical visits at the age of 3,6, 12, 18, 24 and 36 months for clinical examination, sampling of biological specimens, and for presentation of the study diary.

This article is protected by copyright. All rights reserved. 
Nearly $70 \%$ of the participants $(n=557,69.9 \%$ ) completed the follow-up. The drop-out rates were similar in Finland and Estonia (21.8\% and $22.0 \%$, respectively), but only four participants from Russian Karelia completed the study (drop-out rate 95.5\%; Figure 1). Because of this unequal study compliance and remarkable differences in the original cohort sizes, comprehensive analyses could performed only for Finland and Estonia. A shorter, descriptive analysis about results from Russian Karelia was carried out.

The local ethics committees (Ethics committee, Helsinki and Uusimaa Hospital District; Ethics Review Committee on Human Research of the University of Tartu; and Ethics committee, Ministry of Health and Social Development, Karelian Republic of the Russian Federation) had approved the study and parents had provided written informed consents before starting the study procedures.

HLA genotyping. The cord blood samples from the newborn infants were analysed for the presence of HLA DR/DQ genotypes associated with increased risk for T1D with a polymerase chain reactionbased lanthanide-labelled hybridization method, as previously described $(21,22)$. Children positive for DR3-DQ2 (DQA1*05-DQB1*02) and/or DR4-DQ8 (DRB1*04:01/2/4/5/8-DQB1*0302/4) without protective haplotypes (23) were eligible for the study. The participants were classified into HLA risk groups according to presence of the risk haplotypes; DR3-DQ2/DR4-DQ8 heterozygosity indicating highest risk for T1D, and DR4-DQ8/X (X=DR4-DQ8 or a neutral haplotype) or DR3-DQ2/Y (Y=DR3-DQ2 or a neutral haplotype) indicating a moderate risk.

Classification of infections. Illnesses reported by parents in the DIABIMMUNE diary were categorized according to the International Classification of Diseases 10th revision (ICD-10) and transferred into the study database by the study staff. Only illnesses showing clear signs of infections were included in this study (i.e. ICD-10 codes indicating infectious diseases and episodes with only fever but without a local infection focus). Infectious illnesses reported within a week from each other were classified according to the most severe diagnostic code as respiratory, gastrointestinal, other, and unlocalized febrile infection episodes $(20,24)$. As an exception, episodes of otitis media reported

This article is protected by copyright. All rights reserved. 
within four weeks were classified into one episode of reoccurring otitis media. This approach was chosen to reduce overestimation of microbe encounters leading to infections. Fever was defined as peripheral temperature higher than $37.5^{\circ} \mathrm{C}$.

Classifications of medications. The use of medications was reported by parents with brand names and entered into the DIABIMMUNE database by the study staff. Only the use of systemic antibiotics and antipyretic-analgesics were included in the current study. Parents reported the child's age at the start of the drug treatment, its duration, and the reason for it. Antibiotics were classified according to the active ingredient as aminoglycosides, cephalosporins, macrolides, penicillins, combinations of sulfonamides and trimethoprim, and other antibiotics. Antipyretic-analgesics were analysed according to the active ingredient (paracetamol, ibuprofen, naproxen, and acetylsalicylic acid).

Statistical analyses. Data were analysed with IBM SPSS Statistics, version 22.0 and 25.0 (IBM Corp., Armonk, N.Y., USA). The normal distribution of the data was tested with the Kolmogorov-Smirnov test. Comparisons between categorical variables were performed using cross-tabulation and Chisquare test. One-way ANOVA test with Bonferroni post hoc test was used for parametrically distributed variables (mean, standard deviation (SD)). The Mann-Whitney U-test and Kruskal-Wallis test were applied for comparisons of non-parametric variables between groups, and these results are presented as medians and interquartile range (IQR; with the $25^{\text {th }}$ to $75^{\text {th }}$ percentile). In some analyses medians nor the IQRs differed, although the distributions differed significantly between groups. These results are marked with the significant $p$ value and the IQRs are replaced with ranges; no mean ranks are reported. A p-value $<0.05$ was considered to indicate statistical significance.

Each 6 and 12-month interval was analysed separately and children who had dropped out from the study were not considered in the analyses after the drop-out. A child was regarded as a drop-out if he/she had dropped out of the study more than 1 month prior to the end of that interval, i.e. children who dropped out at the age of $\geq 11$ months were included in analyses of the first year of

This article is protected by copyright. All rights reserved. 
life. This 1-month rule was selected because children, who dropped out a few weeks before the interval's actual endpoint, were considered to have reported close to all data at this point.

\section{RESULTS}

The descriptives of the study cohorts are shown in Table 1. Finnish infants carried the DR3-DQ2/Y genotype less frequently, had an older gestational age, and their mothers were older at the delivery of the offspring, compared to Estonians and Russian Karelians. Russian Karelians had the lowest number of siblings at birth (full- and half siblings, twins included) and they were taller at birth than their Finnish and Estonian peers. These background characteristics of the participants did not explain any of the results below. The number of infections in each year and cumulative during the entire follow-up did not differ between HLA risk groups.

A total of 6092 infection episodes were reported during the follow-up, out of which $48.1 \%$ were diagnosed by heath care providers (Finland 51.1\%, Estonia 41.2\%, and Russian Karelia 95.0\%). Close to all children who completed the study had at least one infection during the follow-up (99.8\%). The majority of reported infections were respiratory $(76.4 \%)$, followed by gastrointestinal (8.7\%), unlocalized febrile episodes (7.9\%), and other infections (7.0\%). Fever was reported in $47.3 \%$ of the episodes. A total of 1707 antibiotic treatments and 2053 episodes of the use of antipyreticanalgesic medications were reported. Among those children who completed the study, $75.6 \%$ and 83.1\% had used antibiotics and antipyretic-analgesics, respectively, during the follow-up. The most frequently used antibiotics were penicillins (62.6\%), followed by macrolides (12.9\%), combinations of sulfonamides and trimethoprim (10.9\%), cephalosporins (11.4\%), aminoglycosides (1.2\%), and other antibiotics (1.1\%). Among antipyretic-analgesics, paracetamol was used most frequently (76.3\%; naproxen $15.8 \%$, ibuprofen $7.7 \%$, and acetylsalicylic acid $0.2 \%$ ). The use of naproxen was only reported in Finland (Table 2).

This article is protected by copyright. All rights reserved. 


\section{Finland vs. Estonia}

Compared to Estonians, Finns reported more infections during the first and second year of life (1st year: medians 3.0 (IQR 2.0-5.0) vs. 3.0 (1.0-4.0), p=0.008; 2nd year: 4.0 (3.0-6.0) vs. 3.0 (2.0-4.0), $p<0.001)$. In the first year of life, Finns reported more respiratory infections $(p<0.001)$ and Estonians more other infections $(p=0.004)$, compared to the respective other country. During the second year of life, differences were only seen in the number of respiratory infections, with Finnish children experiencing more of such infections $(p<0.001)$. In the third year of life, there was no difference in the number of infections per child between the countries, but when looking at specific infection types, Finns reported more unlocalized febrile episodes $(p<0.001)$. The number of infections per child per each 6-month interval are shown in Figure 2. In the first and third year of life both countries reported similar proportions of children having at least one infection (Finns $91.4 \%$ and $84.4 \%$, and Estonians $88.6 \%$ and $86.9 \%$, respectively), but in the second year Finns reported a higher proportion of such children (96.1\% vs $91.7 \%, p=0.022$ ). During the entire follow-up, children from Finland had a median of ten (6.8-14.0) infections while Estonians had eight (6.0-11.0; $p<0.001$; Figure 3). However, Estonian children who had at least one infection during the follow-up tended to have their first infection at a slightly younger age than their Finnish peers [4.4 (2.5-6.7) vs. 5.0 (3.1-7.0) months, $\mathrm{p}=0.057]$

The parents reported that the first antibiotic treatment and the first use of an antipyreticanalgesic occurred at a younger age in the Finnish children than in the Estonian participants (1st antibiotic: 10.0 (6.0-16.0) vs. 12.0 (6.5-20.0) months, $p=0.017$; 1st antipyretic-analgesic: 5.5 (3.010.0) vs. 10.0 (6.0-15.6) months, $p<0.001)$. In each year during the follow-up, Finnish children were given more antibiotics and antipyretic-analgesics than their Estonian peers (Figure 4). During the entire follow-up, children from Finland were given on an average three (1-6) antibiotic courses and four (2-6) courses of antipyretic-analgesics, while Estonian children were exposed to only one (0-3) antibiotic and one (0-3) antipyretic-analgesic ( $p<0.001$ regarding both drug classes). Macrolides were used for longer periods of time in Estonia than in Finland [7 (5-7) vs. 3 (3-5) days, $p<0.001$ ], but no 
differences in the duration of treatment were seen in the other groups of antibiotics. Antipyreticanalgesics were also administered for longer periods in Estonia than in Finland [3 (2-3) vs. 2 (1-3) days, $p=0.005]$. The more frequent use of medications in Finland was not explained by the higher number of infections, since Finns used more antibiotic courses per infection $[0.29(0.11-0.50)$ vs. $0.14(0.00-0.31), p<0.001]$ and per infections diagnosed by a healthcare provider $[0.60(0.33-1.00)$ vs $0.40(0.00-0.80), p<0.001)$, as well as more antipyretic-analgesics per infection $[0.38(0.23-0.60)$ vs. $0.17(0.00-0.38), p<0.001]$ and per infections with fever $[1.00(0.46-1.50)$ vs. $0.39(0.14-0.75)$, $\mathrm{p}<0.001]$

\section{Russian Karelia}

Russian Karelians reported their first infection at an age of 6.6 (4.3-9.9) months, which is older than the ages at the first infections in Finland $(p=0.034)$ and Estonia $(p=0.002)$. During the first year of life only $65.4 \%$ of Karelians reported at least one infection and during the second year $60.0 \%$. Karelians reported a median of one infection both in the first and in the second year of life, which is less than the number of infections in Finland and Estonia ( $p<0.001$ compared to Finns and Estonians in both years). Differences were seen in the number of respiratory infections during both years compared to Finland and Estonia, and in the number of other infections during the first year between Russian Karelia and Estonia. Since only four Karelian children remained in the study until the age of 3 years, no analyses were possible during the third year.

The parents of only 17 children (19.1\%) from Russian Karelia reported the use of any antibiotics. Compared to the two other countries, Karelians were exposed to less antibiotics during the first and second year of life (significant between Finland and Russian Karelia; $p=0.001$ and $p<0.001$, respectively), but the first antibiotic was administered at a slightly younger age.

Karelian children, in whom the parents reported the use of antipyretic-analgesics ( $n=17$, 19.1\%) were older than their Finnish peers $[10.0(8.5-13.5)$ vs. $5.5(3.0-10.0)$ months, $p=0.001]$ and about the same age as their Estonian peers at the first introduction of paracetamol or ibuprofen.

This article is protected by copyright. All rights reserved. 
Karelians were exposed to antipyretic-analgesics less frequently than Finns during the first $(p<0.001)$ and second year $(p=0.001)$ of life.

\section{DISCUSSION}

In the current study we found that Finnish children experienced more early childhood infections up to the age of 2.5 years compared to Estonians and Russian Karelians. This was the case especially regarding respiratory infections. Finnish children also used significantly more antibiotics and antipyretic-analgesics during the entire 3-year follow-up.

These results are consistent with our hypothesis, but they do not explain the reason for it. Since these geographically adjacent areas have resembling climatic conditions and quite similar prevalences of HLA-genotypes, but notable differences in the incidences of immune-mediated diseases, the suspicion shifts toward the immune system. With our study design, we could only evaluate microbe exposures leading to clinical infections; subclinical infections could not be assessed. Nonetheless, Russian schoolchildren have been shown to be exposed to microbes, such as Helicobacter pylori, hepatitis A, Coxsackievirus B4, and Toxoplasma gondii, more frequently than Finnish children (25). Russian Karelian young children have also been shown to have a more mature immune response to microbe encounters (26). This demonstrates how higher frequencies of clinical infections are not simply explained by the higher number of microbe encounters. As the hygiene hypothesis suggests, the developing immune system requires microbial encounters to guide its maturation towards self-tolerance and its ability to defend the host against pathogens. The lack of beneficial microbe encounters due to a westernized lifestyle or imbalances in the intestinal microbiome caused by antibiotic treatments (27), could be factors altering the education and maturation of the immune system, and thus leading to more clinical infections, and possible even to immune-mediated diseases later in life.

This article is protected by copyright. All rights reserved. 
As expected, paracetamol was the most commonly used antipyretic-analgesic medication. Only 26 children had used paracetamol up to the age of 3 months. Acetylsalicylic acid was reported to be used in Finland and Estonia by only three children (one used it twice) for fever, flu, and postoperatively at 6 to 30 months of age. This shows that acetylsalicylic acid no more is the primary antipyretic-analgesic for children, which could potentially be explained by increased awareness of Reye's syndrome. Naproxen was reported to be used only in Finland. How this might explain the results remains unclear, but compared to ibuprofen and paracetamol, naproxen has a more longstanding and a stronger immunomodulatory effect. The more extensive use of antibiotics and antipyretic-analgesics in Finland was not explained by the higher number of infections, since Finnish children used more of both drug classes per infection episode.

The strength of our study is that the subjects are from three countries with remarkable differences in socio-economic conditions, but with similar HLA-genotypes. Another asset is that infections and medications were monitored continuously by parents. By inspecting medical records and records of prescribed medications, the number of illnesses common in childhood, such as common cold and other mild infections, and the use of over-the-counter medicines, such as antipyretic-analgesics, would have been underestimated. However, since a total of $52 \%$ of the infections were not diagnosed by a healthcare provider, subjective and cultural differences in parental conceptions of symptoms are possible. The high proportion of infections diagnosed by a healthcare provider in Russian Karelia (95\%, vs $51 \%$ in Finland and $41 \%$ in Estonia) reflects on differences in the healthcare systems, since in Russia a family doctor is consulted at a lower threshold.

This study has some limitations. All study subjects carried HLA-conferred susceptibility to T1D, and the results might therefore not apply to the general population. Since the HLA genotypes included are known to predispose to autoimmune disorders, these children might by default have a weaker immune system or a less favourable intestinal microbiome, which in turn may be reflected in a higher predisposition to clinical infections. However, these HLA genotypes are common in the 
general population and only a small proportion of people carrying these genotypes develop T1D. We screened almost 9000 children and 19\% of them carried predisposing genotypes (Finland 23\%, Estonia 16\%, and Russian Karelia 17\%). Two children were diagnosed with T1D during the follow-up, and by September 201812 children (1.5\%) have been diagnosed with T1D. Children who develop prediabetes and T1D have been shown to have more infections in early childhood, especially during the first year of life, both compared to the general population and to healthy children with HLAconferred disease susceptibility $(20,28-31)$.

The low enrolment rate and the high drop-out rate in Russian Karelia did not allow us to perform proper analyses between all three countries. Karelian children used clearly less antibiotics and a broader spectrum of different antibiotics, which fits into earlier observations about more conservative antibiotic use in Russia (32). Russian Karelians tended to be treated with homeopathic medications instead of antibiotics and antipyretic-analgesics, which may explain some of the differences in the reported frequencies of antibiotics and antipyretic-analgesics. We recommend that the results regarding Russian Karelia should be interpreted critically since, in addition to the small study cohort, Karelians reported no neonatal infections (age $<0.5$ months) and no post term births ( $>42$ weeks). In contrast to Finland and Estonia, antibiotics can often be bought without a prescription in Russia (33). This did not, however, result in a more extensive use of antibiotics in Karelia among young children.

In conclusion, we found that children from Finland have more infections and they use more antibiotics and antipyretic-analgesics in early childhood, compared to Estonians and Russian Karelians. In line with the hygiene hypothesis, this could indicate a weaker immune system in Finns, due to too sparse microbe encounters when the immune system is maturating. However, other factors, such as environmental and genetic, cannot be ruled out. The extensive use of antibiotics, particularly in Finland, is concerning. Antibiotics should not be used without appropriate diagnostics, since childhood infections is mostly caused by viruses, and the extensive use of antibiotics leads to increasing microbe resistance and unfavourable changes in the gut microbiome.

This article is protected by copyright. All rights reserved. 


\section{Acknowledgements}

The authors thank all the participating children and families in the DIABIMMUNE study as well as the physicians, nurses, and technicians in the DIABIMMUNE study centres and laboratories.

The members of the DIABIMMUNE Study Group are Mikael Knip (Children's Hospital, University of Helsinki, Finland), Katriina Koski (Clinicum, University of Helsinki, Finland), Matti Koski (Clinicum, University of Helsinki, Finland), Taina Härkönen (Children's Hospital, University of Helsinki, Finland), Heli Siljander (Children's Hospital, University of Helsinki, Finland), Samppa Ryhänen (Children's Hospital, University of Helsinki, Finland), Anu-Maaria Hämäläinen (Jorvi Hospital, Helsinki University Hospital, Finland), Anne Ormisson (Department of Pediatrics, Tartu University Hospital, Estonia), Aleksandr Peet (Department of Pediatrics, Tartu University Hospital, Estonia), Vallo Tillmann (Department of Pediatrics, Tartu University Hospital, Estonia), Valentina Ulich (Ministry of Health and Social Development, Karelian Republic of the Russian Federation, Russia), Elena Kuzmicheva (Ministry of Health and Social Development, Karelian Republic of the Russian Federation, Russia), Sergei Mokurov (Ministry of Health and Social Development, Karelian Republic of the Russian Federation, Russia), Svetlana Markova (Children's Republic Hospital, Karelian Republic of the Russian Federation, Russia), Svetlana Pylova (Children's Republic Hospital, Karelian Republic of the Russian Federation, Russia), Marina Isakova (Perinatal Center, Karelian Republic of the Russian Federation, Russia), Elena Shakurova (Perinatal Center, Karelian Republic of the Russian Federation, Russia), Vladimir Petrov (Maternity Hospital N8 1, Petrozavodsk, Russia), Natalya V. Dorshakova (Petrozavodsk State University, Russia), Tatyana Karapetyan (Petrozavodsk State University, Russia), Tatyana Varlamova (Petrozavodsk State University, Russia), Jorma Ilonen (Immunogenetics Laboratory, University of Turku, Finland), Minna Kiviniemi (Immunogenetics Laboratory, University of Turku, Finland), Kristi Alnek (Department of Immunology, University of Tartu, Estonia), Helis Janson (Department of Immunology, University of Tartu, Estonia), Raivo Uibo (Department of Immunology, University of Tartu, Estonia), Erika von Mutius (Children's Hospital, Ludwig Maximilians Universität, Munchen, Germany), Juliane Weber (Children's Hospital, Ludwig Maximilians

This article is protected by copyright. All rights reserved. 
Universität, Munchen, Germany), Helena Ahlfors (Turku Centre of Biotechnology, University of Turku and Åbo Akademi, Finland), Henna Kallionpää (Turku Centre of Biotechnology, University of Turku and Åbo Akademi, Finland), Essi Laajala (Turku Centre of Biotechnology, University of Turku and Åbo Akademi, Finland), Harri Lähdesmäki (Turku Centre of Biotechnology, University of Turku and Åbo Akademi, Finland), Riitta Lahesmaa (Turku Centre of Biotechnology, University of Turku and Åbo Akademi, Finland), Robert Moulder (Turku Centre of Biotechnology, University of Turku and Åbo Akademi, Finland), Janne Nieminen (Department of Vaccination and Immune Protection, National Institute for Health and Welfare, Helsinki, Finland), Terhi Ruohtula (Department of Vaccination and Immune Protection, National Institute for Health and Welfare, Helsinki, Finland), Outi Vaarala (Department of Vaccination and Immune Protection, National Institute for Health and Welfare, Helsinki, Finland), Hanna Honkanen (Department of Virology, University of Tampere and Tampere University Hospital, Finland), Heikki Hyöty (Department of Virology, University of Tampere and Tampere University Hospital, Finland), Anita Kondrashova (Department of Virology, University of Tampere and Tampere University Hospital, Finland), Sami Oikarinen (Department of Virology, University of Tampere and Tampere University Hospital, Finland), Hermie J.M. Harmsen (University Medical Center Groningen, The Netherlands), Marcus C. De Goffau (University Medical Center Groningen, The Netherlands), Gjalt Welling (University Medical Center Groningen, The Netherlands), Kirsi Alahuhta (Department for Welfare and Health Promotion, National Institute for Health and Welfare, Helsinki, Finland), Suvi M. Virtanen (Department for Welfare and Health Promotion, National Institute for Health and Welfare, Helsinki, Finland)

\section{Conflict of Interest}

The authors declare no conflict of interest.

This article is protected by copyright. All rights reserved. 


\section{Funding}

The work was supported by the European Union Seventh Framework Programme (grant no.

202063), the Academy of Finland (Decision No. 292538, and Centre of Excellence in Molecular

Systems Immunology and Physiology Research, Decision No. 250114), the Liv och Hälsa Fund, the

Estonian Research Council (grant PUT1382), Finska Läkaresällskapet and Stiftelsen Dorothea Olivia,

Karl Walter och Jan Walter Perkléns Minne.

\section{References}

(1) Kusel MM, de Klerk NH, Holt PG, Kebadze T, Johnston SL, Sly PD. Role of respiratory viruses in acute upper and lower respiratory tract illness in the first year of life: a birth cohort study. Pediatr Infect Dis J 2006; 25: 680-6.

(2) Regamey N, Kaiser L, Roiha HL, Deffernez C, Kuehni CE, Latzin P, et al. Viral etiology of acute respiratory infections with cough in infancy: a community-based birth cohort study. Pediatr Infect Dis J 2008; 27: 100-5.

(3) Nyquist AC, Gonzales R, Steiner JF, Sande MA. Antibiotic prescribing for children with colds, upper respiratory tract infections, and bronchitis. JAMA 1998; 279: 875-7.

(4) Jacobs RF. Judicious use of antibiotics for common pediatric respiratory infections. Pediatr Infect Dis J 2000; 19: 938-43.

(5) Wise R, Hart T, Cars O, Streulens M, Helmuth R, Huovinen P, et al. Antimicrobial resistance is a major threat to public health. BMJ 1998; 317: 609-10.

(6) Lu CY, Ni YH. Gut microbiota and the development of pediatric diseases. J Gastroenterol 2015; 50: 720-6.

(7) Vangay P, Ward T, Gerber JS, Knights D. Antibiotics, pediatric dysbiosis, and disease. Cell Host Microbe 2015; 17: 553-64.

(8) Arrieta MC, Stiemsma LT, Dimitriu PA, Thorson L, Russell S, Yurist-Doutsch S, et al. Early infancy microbial and metabolic alterations affect risk of childhood asthma. Sci Transl Med 2015; 7: 307ra152.

(9) Kozyrskyj AL, Ernst P, Becker AB. Increased risk of childhood asthma from antibiotic use in early life. Chest 2007; 131: 1753-9.

(10) Arvonen M, Virta L, Pokka T, Kroger L, Vahasalo P. Repeated exposure to antibiotics in infancy: a predisposing factor for juvenile idiopathic arthritis or a sign of this group's greater susceptibility to infections? J Rheumatol 2015; 42: 521-6.

(11) Slykerman RF, Thompson J, Waldie KE, Murphy R, Wall C, Mitchell EA. Antibiotics in the first year of life and subsequent neurocognitive outcomes. Acta Paediatr 2017; 106: 87-94.

(12) Bailey LC, Forrest CB, Zhang P, Richards TM, Livshits A, DeRusso PA. Association of antibiotics in infancy with early childhood obesity. JAMA Pediatr 2014; 168: 1063-9.

(13) Strachan DP. Hay fever, hygiene, and household size. BMJ 1989; 299: 1259-60.

(14) Kallionpaa H, Laajala E, Oling V, Harkonen T, Tillmann V, Dorshakova NV, et al. Standard of hygiene and immune adaptation in newborn infants. Clin Immunol 2014; 155: 136-47.

(15) Kondrashova A, Reunanen A, Romanov A, Karvonen A, Viskari H, Vesikari T, et al. A six-fold gradient in the incidence of type 1 diabetes at the eastern border of Finland. Ann Med 2005; 37: 67-72.

(16) Teeaar T, Liivak N, Heilman K, Kool P, Sor R, Paal M, et al. Increasing incidence of childhood-onset type 1 diabetes mellitus among Estonian children in 1999-2006. Time trend analysis 1983-2006. Pediatr Diabetes 2010; 11: 107-10.

(17) Harjutsalo V, Sund R, Knip M, Groop PH. Incidence of type 1 diabetes in Finland. JAMA 2013; 310: 427-8.

(18) Laatikainen T, von Hertzen L, Koskinen JP, Makela MJ, Jousilahti P, Kosunen TU, et al. Allergy gap between Finnish and Russian Karelia on increase. Allergy 2011; 66: 886-92.

(19) Simre K, Uibo O, Peet A, Tillmann V, Kool P, Hamalainen AM, et al. Exploring the risk factors for differences in the cumulative incidence of coeliac disease in two neighboring countries: the prospective DIABIMMUNE study. Dig Liver Dis 2016; 48: 1296-301.

(20) Mustonen N, Siljander H, Peet A, Tillmann V, Harkonen T, llonen J, et al. Early childhood infections precede development of beta-cell autoimmunity and type 1 diabetes in children with HLA-conferred disease risk. Pediatr Diabetes 2018; 19: 293-9.

This article is protected by copyright. All rights reserved. 
(21) Peet A, Kool P, llonen J, Knip M, Tillmann V, DIABIMMUNE Study Group. Birth weight in newborn infants with different diabetes-associated HLA genotypes in three neighbouring countries: Finland, Estonia and Russian Karelia. Diabetes Metab Res Rev 2012; 28: 455-61.

(22) Hermann R, Turpeinen H, Laine AP, Veijola R, Knip M, Simell O, et al. HLA DR-DQ-encoded genetic determinants of childhood-onset type 1 diabetes in Finland: an analysis of 622 nuclear families. Tissue Antigens 2003; 62: 162-9.

(23) Ilonen J, Kiviniemi M, Lempainen J, Simell O, Toppari J, Veijola R, et al. Genetic susceptibility to type 1 diabetes in childhood - estimation of HLA class II associated disease risk and class II effect in various phases of islet autoimmunity. Pediatr Diabetes 2016; 17 Suppl 22:8-16.

(24) Lonnrot M, Lynch K, Larsson HE, Lernmark A, Rewers M, Hagopian W, et al. A method for reporting and classifying acute infectious diseases in a prospective study of young children: TEDDY. BMC Pediatr 2015; 15: 24.

(25) Seiskari T, Kondrashova A, Viskari H, Kaila M, Haapala A-, Aittoniemi J, et al. Allergic sensitization and microbial load - a comparison between Finland and Russian Karelia. Clin Exp Immunol 2007; 148: 47-52.

(26) Vatanen T, Kostic AD, d'Hennezel E, Siljander H, Franzosa EA, Yassour M, et al. Variation in microbiome LPS immunogenicity contributes to autoimmunity in humans. Cell 2016; 165: 842-53.

(27) Yassour M, Vatanen T, Siljander H, Hamalainen AM, Harkonen T, Ryhanen SJ, et al. Natural history of the infant gut microbiome and impact of antibiotic treatment on bacterial strain diversity and stability. Sci Trans/ Med 2016; 8: 343ra81.

(28) Rasmussen T, Witso E, Tapia G, Stene LC, Ronningen KS. Self-reported lower respiratory tract infections and development of islet autoimmunity in children with the type 1 diabetes high-risk HLA genotype: the MIDIA study. Diabetes Metab Res Rev 2011; 27: 834-37.

(29) Beyerlein A, Donnachie E, Jergens S, Ziegler AG. Infections in early life and development of type 1 diabetes. JAMA 2016; 315: 1899-901.

(30) Beyerlein A, Wehweck F, Ziegler AG, Pflueger M. Respiratory infections in early life and the development of islet autoimmunity in children at increased type 1 diabetes risk: evidence from the BABYDIET study. JAMA Pediatr 2013; 167: 800-7.

(31) Snell-Bergeon JK, Smith J, Dong F, Baron AE, Barriga K, Norris JM, et al. Early childhood infections and the risk of islet autoimmunity: the Diabetes Autoimmunity Study in the Young (DAISY). Diabetes Care 2012; 35: 2553-8.

(32) Stratchounski L, Bedenkov A, Hryniewicz W, Krcmery V, Ludwig E, Semenov V. The usage of antibiotics in Russia and some countries in Eastern Europe. Int J Antimicrob Agents 2001; 18: 283-6.

(33) Stratchounski LS, Andreeva IV, Ratchina SA, Galkin DV, Petrotchenkova NA, Demin AA, et al. The inventory of antibiotics in Russian home medicine cabinets. Clin Infect Dis 2003; 37: 498-505.

This article is protected by copyright. All rights reserved. 
Tables

Table 1 Descriptive characteristics of the study cohorts

\begin{tabular}{|c|c|c|c|}
\hline & Finland & Estonia & Russian Karelia \\
\hline & $n=386$ & $n=322$ & $n=89$ \\
\hline Proportion of males (\%) & 50.5 & 51.2 & 57.3 \\
\hline Maternal age at delivery, years (mean, SD) ${ }^{a}$ & $31.2(4.5)$ & $28.9(5.7)$ & $27.6(4.8)$ \\
\hline Number of siblings at birth (median, range) & $0(0-6)$ & $1(0-6)$ & $0(0-3)$ \\
\hline Gestational age, weeks (median, IQR) ${ }^{\mathrm{c}}$ & $40.3(39.3-41.0)$ & $40.0(39.0-40.9)$ & $40.0(39.0-40.0)$ \\
\hline Birth weight, $g$ (mean, SD) & $3565.9(473.2)$ & $3579.2(511.0)$ & $3521.3(477.4)$ \\
\hline Birth length, $\mathrm{cm}$ (median, IQR) ${ }^{\mathrm{d}}$ & $51.0(49.0-52.0)$ & $51.0(49.0-52.0)$ & $52.0(51.0-53.5)$ \\
\hline Birth head circumference, $\mathrm{cm}$ (median, IQR) & $35.0(34.0-36.0)$ & $35.0(34.0-36.0)$ & $35.0(34.0-36.0)$ \\
\hline Caesarean section (\%) & 9.6 & 10.6 & 14.6 \\
\hline \multicolumn{4}{|l|}{ HLA risk group (\%) ${ }^{\mathrm{e}}$} \\
\hline DR3-DQ2 / DR4-DQ8 & 9.1 & 9.6 & 6.7 \\
\hline DR4-DQ8 / $X^{f}$ & 39.1 & 28.9 & 30.3 \\
\hline DR3-DQ2 / $Y^{g}$ & 51.8 & 61.5 & 62.9 \\
\hline
\end{tabular}

a significant between Finland \& Estonia $(p<0.001)$, and Finland \& Russian Karelia $(p<0.001)$

${ }^{b}$ significant between Finland \& Russian Karelia $(p=0.004)$, and Estonia \& Russian Karelia $(p<0.001)$

${ }^{c}$ significant between Finland \& Russian Karelia $(p=0.001)$

${ }^{d}$ significant between Finland \& Russian Karelia $(p<0.001)$, and Estonia \& Russian Karelia $(p<0.001)$

${ }^{\mathrm{e}} \mathrm{p}=0.041$ with Chi-square test

${ }^{f} \mathrm{X}=\mathrm{DR} 4-\mathrm{DQ} 8$ or a neutral haplotype

${ }^{\mathrm{g}} \mathrm{Y}=\mathrm{DR} 3-\mathrm{DQ} 2$ or a neutral haplotype

This article is protected by copyright. All rights reserved. 
Table 2 Number (\%) of all reported infection episodes, antibiotics, and antipyretic-analgesic medications in each country.

\begin{tabular}{lccc}
\hline & Finland & Estonia & Russian Karelia \\
\hline Infection episodes & $3481(100)$ & $2470(100)$ & $141(100)$ \\
\hline Respiratory & $2734(78.5)$ & $1808(73.2)$ & $114(81)$ \\
Gastrointestinal & $267(7.7)$ & $254(10.3)$ & $10(7)$ \\
Other & $191(5.5)$ & $223(9.0)$ & $11(8)$ \\
Unlocalized febrile & $289(8.3)$ & $185(7.5)$ & $6(4)$ \\
\hline Antibiotics & $1175(100)$ & $499(100)$ & $33(100)$ \\
\hline Aminoglycosides & $1(0.1)$ & $19(3.8)$ & $1(3)$ \\
Cephalosporins & $136(11.6)$ & $51(10.2)$ & $7(21)$ \\
Macrolides & $180(15.3)$ & $33(6.6)$ & $7(21)$ \\
Penicillins & $705(60.0)$ & $351(70.3)$ & $12(36)$ \\
Sulfonamides and & $144(12.3)$ & $41(8.2)$ & $0(0)$ \\
trimethoprim & $9(0.8)$ & $4(0.8)$ & $6(18)$ \\
Other antibiotics & $1467(100)$ & $557(100)$ & $29(100)$ \\
\hline Antipyretic-analgesics & $1032(70.3)$ & $513(92.1)$ & $21(72)$ \\
\hline Paracetamol & $108(7.4)$ & $43(7.7)$ & $8(28)$ \\
Ibuprofen & $324(22.1)$ & $0(0.0)$ & $0(0)$ \\
Naproxen & $3(0.2)$ & $1(0.2)$ & $0(0)$ \\
Acetylsalicylic acid & & &
\end{tabular}

This article is protected by copyright. All rights reserved. 


\section{Figure legends}

Figure 1. Participating children from each county; from HLA-screening to those who completed the follow-up. $70 \%$ completed the follow-up. Drop-out rates were 22\% in Finland and Estonia, and 96\% in Russian Karelia.

Figure 2. Mean number of all infections per 6-month intervals (drop-outs excluded at each interval). Comparisons were made using Mann-Whitney $U$ test, and significant $p$-values are marked $\left({ }^{* *} p<0.01\right.$ and $\left.{ }^{* * *} p<0.001\right)$.

Figure 3. Mean number of all reported infections during the entire follow-up. Children who dropped out before the end of the study were excluded. Infections were classified into respiratory, gastrointestinal, other, and unlocalized febrile infection episodes according to the most severe ICD10 code. Comparisons were made using Mann-Whitney $U$ test, and significant $p$-values are marked $\left({ }^{*} p<0.05, * * p<0.01\right.$, and $\left.{ }^{* * *} p<0.001\right)$.

Figure 4. Mean number of all antibiotics and antipyretic-analgesics reported per year of participating in the study. Comparisons were made using Mann-Whitney $U$ test, and significant $p$-values are marked $(* p<0.05$ and $* * * p<0.001)$.

This article is protected by copyright. All rights reserved. 


\section{Figures}

Figure 1

\begin{tabular}{|c|c|c|c|c|}
\hline 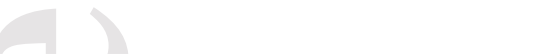 & Finland & Estonia & Russian Karelia & Total \\
\hline Screened for HLA genotypes & 3105 & 2714 & 3044 & 8863 \\
\hline & \& & 民 & $\square$ & 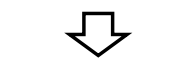 \\
\hline $\begin{array}{l}\text { HLA eligible } \\
\text { (\% of all screened) }\end{array}$ & $713(23.0)$ & $426(15.7)$ & 514 (16.9) & $1653(18.7)$ \\
\hline$y$ & 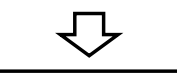 & 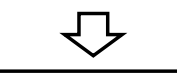 & $\square$ & 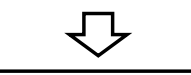 \\
\hline \multirow[t]{2}{*}{ Enrolled in the study } & 387 & 330 & 118 & 835 \\
\hline & ए & 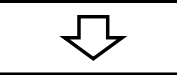 & $\square$ & Z \\
\hline Included in this study * & 386 & 322 & 89 & 797 \\
\hline \multirow{2}{*}{$\begin{array}{l}\text { Still in the study after the 1st year } \\
\text { of life }\end{array}$} & 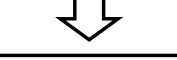 & 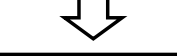 & 4 & 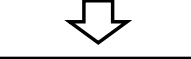 \\
\hline & $337(87.3)$ & $297(92.2)$ & $52(58.4)$ & $686(86.1)$ \\
\hline \multirow{3}{*}{$\begin{array}{l}\text { Still in the study after the } 2 \text { nd year } \\
\text { of life }\end{array}$} & 民 & 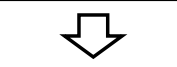 & ■ & 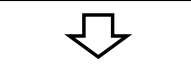 \\
\hline & $311(80.6)$ & $276(85.7)$ & $20(22.3)$ & $607(76.2)$ \\
\hline & 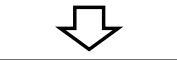 & 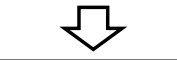 & 2 & 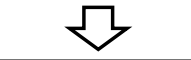 \\
\hline $\begin{array}{l}\text { Completed the } 3 \text { year follow-up } \\
\text { (\% of those included in the study) }\end{array}$ & $302(78.2)$ & $251(78.0)$ & $4(4.5)$ & 557 (69.9) \\
\hline
\end{tabular}

* Participants $(n=38)$ were excluded because of missing data.

This article is protected by copyright. All rights reserved. 


\section{Figure 2}

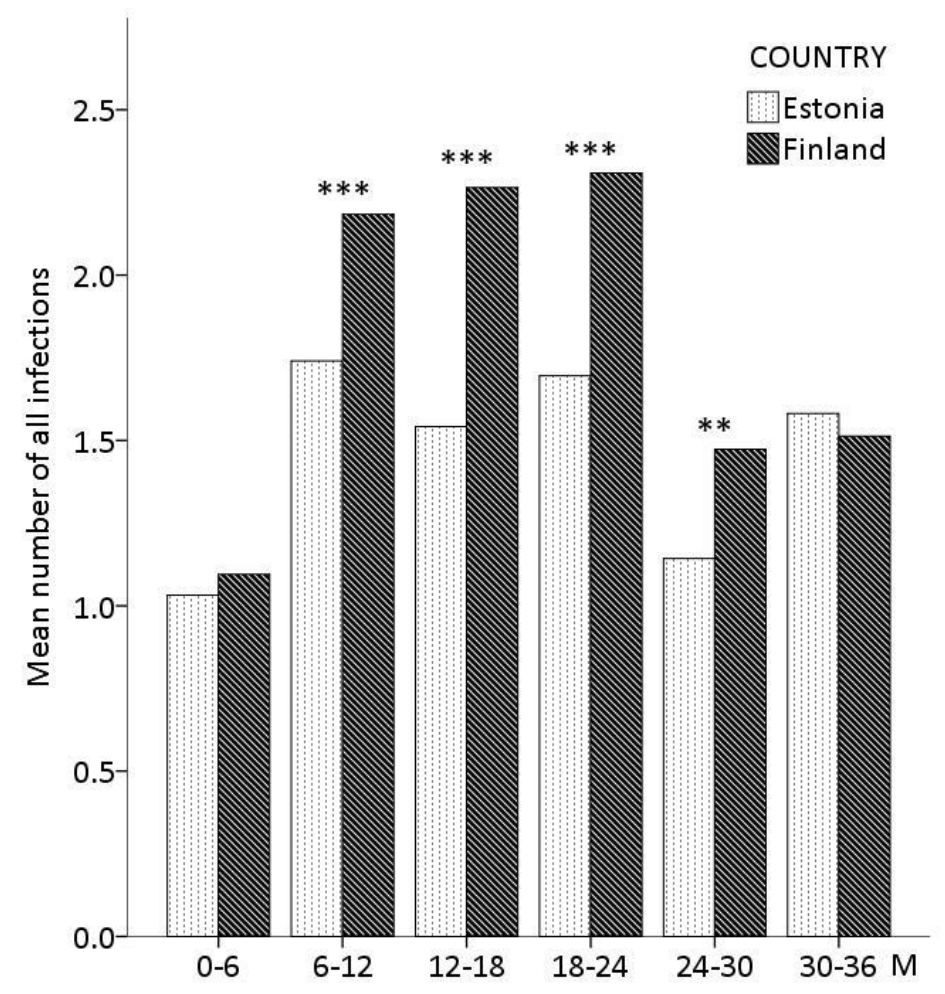

Figure 3

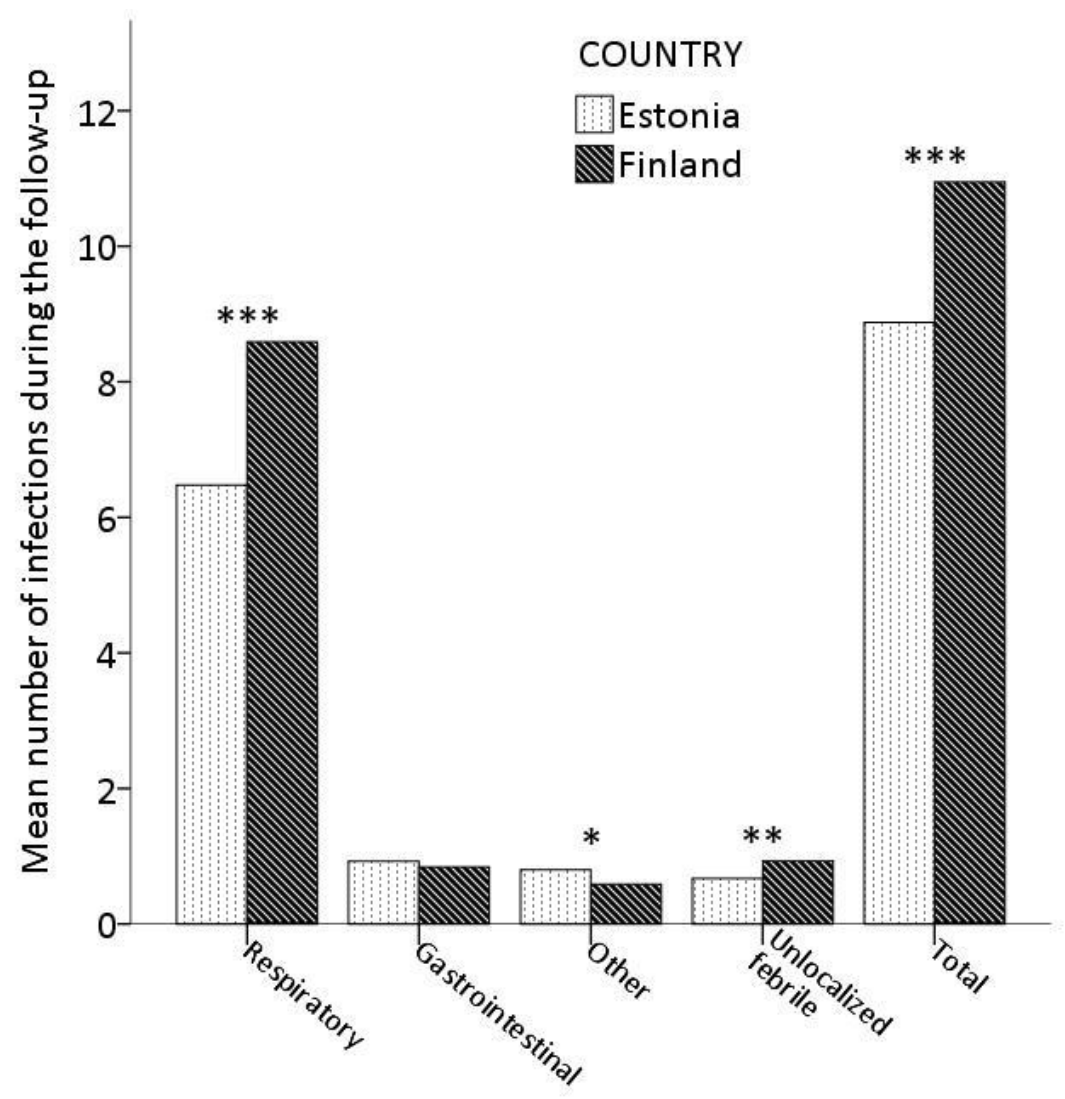

This article is protected by copyright. All rights reserved. 


\section{Figure 4}

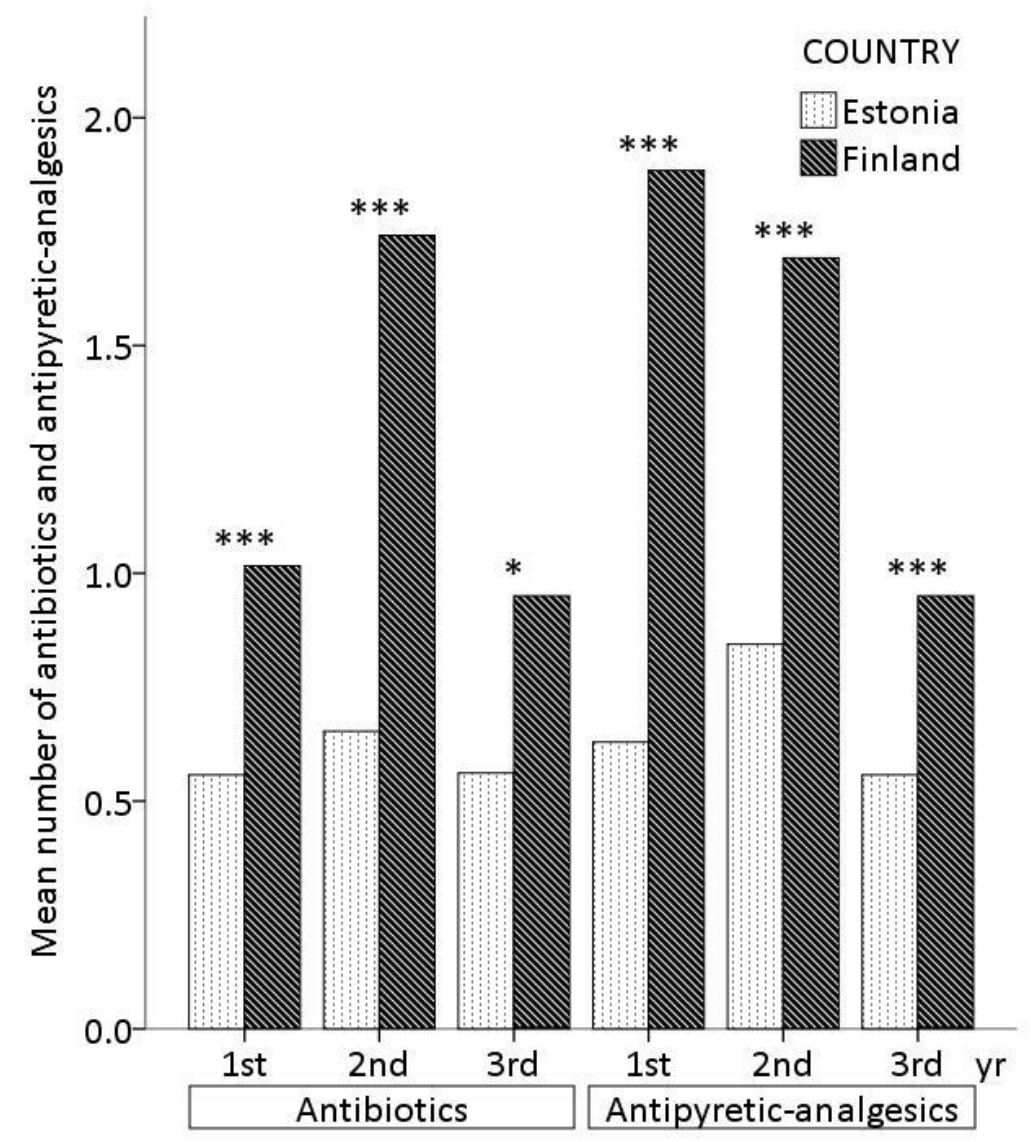

This article is protected by copyright. All rights reserved. 